\title{
Publisher Correction: Capturing variation impact on molecular interactions in the IMEx Consortium mutations data set
}

The IMEx Consortium Curators", N. del-Toro ${ }^{1}$, M. Duesbury ${ }^{1}$, M. Koch ${ }^{1,2}$, L. Perfetto ${ }^{1}$, A. Shrivastava (1) 1 ,

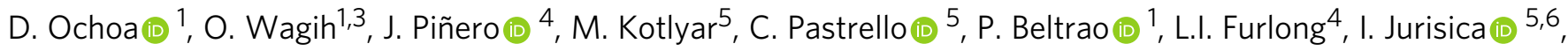
H. Hermjakob (i) ${ }^{1,7}$, S. Orchard ${ }^{1} \&$ P. Porras (i) ${ }^{1}$

Correction to: Nature Communications https://doi.org/10.1038/s41467-018-07709-6; published online 02 January 2019

In the original HTML version of this Article, the order of authors within the author list was incorrect. The IMEx Consortium contributing authors were incorrectly listed as the last author and should have been listed as the first author. This error has been corrected in the HTML version of the Article; the PDF version was correct at the time of publication.

Published online: 04 March 2019

\begin{abstract}
(c) (i) Open Access This article is licensed under a Creative Commons Attribution 4.0 International License, which permits use, sharing, adaptation, distribution and reproduction in any medium or format, as long as you give appropriate credit to the original author(s) and the source, provide a link to the Creative Commons license, and indicate if changes were made. The images or other third party material in this article are included in the article's Creative Commons license, unless indicated otherwise in a credit line to the material. If material is not included in the article's Creative Commons license and your intended use is not permitted by statutory regulation or exceeds the permitted use, you will need to obtain permission directly from the copyright holder. To view a copy of this license, visit http://creativecommons.org/licenses/by/4.0/.
\end{abstract}

(C) The Author(s) 2019

\section{IMEx Consortium contributing authors}

IntAct team: J. Khadake ${ }^{1}$, B. Meldal ${ }^{1}$, S. Panni ${ }^{8}$, D. Thorneycroft ${ }^{1}$, K. van Roey ${ }^{1}$, DIP team: S. Abbani ${ }^{9}$, L. Salwinski ${ }^{9}$, M. Pellegrini ${ }^{9}$, MINT team: M. Iannuccelli ${ }^{10}$, L. Licata ${ }^{10}$, G. Cesareni ${ }^{10}$, SwissProt-UniProt team: B. Roechert ${ }^{11}$, A. Bridge ${ }^{11}$, M.G. Ammari ${ }^{12}$, F. McCarthy ${ }^{12}$, I2D team: F. Broackes-Carter ${ }^{5}$, BHF-UCL team: N.H. Campbell ${ }^{13}$, A.N. Melidoni ${ }^{1,13}$, M. Rodriguez-Lopez ${ }^{1,13}$, R.C. Lovering ${ }^{13}$, MBInfo team: S. Jagannathan ${ }^{14}$, InnateDB team: C. Chen ${ }^{15}$, D.J. Lynn ${ }^{16,17}$, MatrixDB team: S. Ricard-Blum ${ }^{18}$,

\footnotetext{
${ }^{1}$ European Bioinformatics Institute (EMBL-EBI), European Molecular Biology Laboratory, Wellcome Genome Campus, Hinxton CB10 1SD, UK. ${ }^{2}$ Novartis Institutes for BioMedical Research (NIBR), Maulbeerstrasse 66, 4058 Basel, Canton of Basel-Stadt, Switzerland. ${ }^{3}$ Deep Genomics, MaRS Centre, 661 University Ave, Suite 480, Toronto, ON M5G 1M1, Canada. ${ }^{4}$ Research Programme on Biomedical Informatics (GRIB), Department of Experimental and Health Sciences (DCEXS), Hospital del Mar Medical Research Institute (IMIM), Universitat Pompeu Fabra (UPF), 08003 Barcelona, Spain. ${ }^{5}$ Krembil Research Institute, Data Science Discovery Centre for Chronic Diseases, University Health Network, 5KD-407, 60 Leonard Avenue, Toronto, ON M5T 0S8, Canada. ${ }^{6}$ Departments of Medical Biophysics and Computer Science, University of Toronto, Toronto M4B 1B5, Canada. ${ }^{7}$ State Key Laboratory of Proteomics, Beijing Proteome Research Center, National Center for Protein Sciences, Beijing Institute of Life Omics, 102206 Beijing, China. *A full list of consortium members appears at the end of the paper. Correspondence and requests for materials should be addressed to P.P. (email: pporras@ebi.ac.uk)
} 


\section{Molecular Connections team: U. Mahadevan ${ }^{19} \&$ A. Raghunath ${ }^{19}$}

${ }^{8}$ DiBEST Department, University of Calabria, Via Pietro Bucci, Rende (CS) 87036, Italy. ${ }^{9}$ Los Angeles Department of Energy Institute for Genomics and Proteomics, University of California, Los Angeles, CA 90001, USA. ${ }^{10}$ Department of Biology, University of Rome Tor Vergata, Via della Ricerca Scientifica, 00118 Rome, Italy. ${ }^{11}$ Swiss-Prot group, SIB Swiss Institute of Bioinformatics, CMU 1, Rue Michel Servet, 1211 Geneva 4, Switzerland.

${ }^{12}$ School of Animal and Comparative Biomedical Sciences, University of Arizona, Tucson, AZ 85721, USA. ${ }^{13}$ Functional Gene Annotation, Institute of Cardiovascular Science, University College London, London 56273, UK. ${ }^{14}$ Mechanobiology Institute, National University of Singapore, T-Lab \#05-01, 5 A Engineering Drive 1, Singapore 117411, Singapore. ${ }^{15}$ Centre for Microbial Diseases and Immunity Research, University of British Columbia, Lower Mall, Vancouver 2259, Canada. ${ }^{16}$ South Australian Health and Medical Research Institute, EMBL Australia Group, North Terrace, Adelaide, SA 5001, Australia. ${ }^{17}$ The College of Medicine and Public Health, Flinders University, Bedford Park, SA 5042, Australia. ${ }^{18}$ Univ. Lyon, ICBMS, UMR 5246 CNRS, Université Lyon 1, Villeurbanne Cedex, 69622 Lyon, France. ${ }^{19}$ Molecular Connections Pvt. Ltd., Kandala Mansions, $2 / 2$ Kariappa Road, Basavangudi, Bangalore 560004, India 